\title{
Detecting Changes in Forest Vegetation using Multitemporal Landsat TM Data -A case study in the Shibata Forest, Niigata Prefecture--
}

\author{
I Nengah Surati Jaya* and Shogo Kobayashi*
}

\begin{abstract}
This paper outlines three change detection methods, i.e., (1) direct multidate classification (MDC), (2) 12-dimensional multitemporal principal component (MPC) and (3) 2-dimensional multitemporal principal component, to detect specific changes in forest cover due to new artificial regeneration, natural growth and forest cutting. Of these 3 techniques, the MDC technique which simply classifies the multidate bands directly consistently provided better delineation of forest change. In the selection of band dimensionality, the 12 dimensional MPC is the most effective. Not only this technique can reduce the dimensionality of the original data, but also effectively picks up the change of interest and provides nearly as the first technique. For all date-pairs (3- to 7-year intervals) the changes due to forest cutting and new artificial regeneration and tree height growth of young plantations were detected; however, the height growth of the larger trees, i.e., S1-S2/3, P1-P2 and P2-P3, could not be detected. As indicated in this study, as the time interval increases, the ability of multidate TM to detect forest cover change increases. Within the young forest plantation, differences in the density of under-story vegetation of Japanese cedar seedlings sometimes led to misclassification.
\end{abstract}

Keyword: change detection, forest cover change, direct multidate classification, 12- and 2-dimensional multitemporal principal components.

\section{INTRODUCTION}

The increasing number of new and improved sensors with finer resolution capabilities of remotely-sensed data acquired by land-observation satellites, such as Landsat, SPOT, ERS-1, RADARSAT and JERS-1, has been accompanied by increasing interest in evaluating their capability to delineate forest cover, particularly in documenting the rate and distribution of forest cover change. Monitoring forest change using conventional methods is often inconsistent among analysts because these methods are based solely on the interpreter's skill. Although there have been numerous studies using remotely-sensed data for detecting land cover changes (e.g., AdENIYI 1985; AlWASHE and BOKHARI 1993; AWAYA et al. 1994; EKSTRAND 1990; ForAN

* Graduate School of Science \& Technology, Niigata University, 8050 Ikarashi Ninocho, Niigata 950-21 Japan
1987; Fung 1990; Hallum 1993; Jensen et al. 1993; NeLSON 1983; Pylon et al. 1988; and Weismiller et al. 1977), the change detection of detailed forest classes has not been fully documented. This paper emphasizes upon strategies for identifying appropriate change detection logic and detecting forest cover changes, particularly changes due to natural growth, artificial regeneration and forest cutting, between two points in time. A more sophisticated change detection method to diagnose forest growth stages based on an image data base consisting of multitemporal satellite data has been described by SENOO (1994).

Our earlier study (JAYA and KOBAYASHi 1995) showed that detailed forest cover types, such as hardwoods, bush/ shrub, mixed forest, tree-height classes of Japanese cedar and pine etc., were reliably classified using single-date TM data. From the monitoring point of view, multidate TM data should be useful for detecting forest changes between two or more dates. Since it would be more desirable for implementation reasons, this study applied a simpler approach without employing atmospheric and topographic 
correction. More complex methods usually require more carefully drawn data inputs together with more thorough user understanding to achieve acceptable results.

The objective of this study is to evaluate how well forest cover changes could be detected between certain dates with TM data using computer-assisted analysis techniques. A quantitative approach was selected to avoid a completely subjective assessment. An additional objective of this study is to evaluate the three change detection methods applied here.

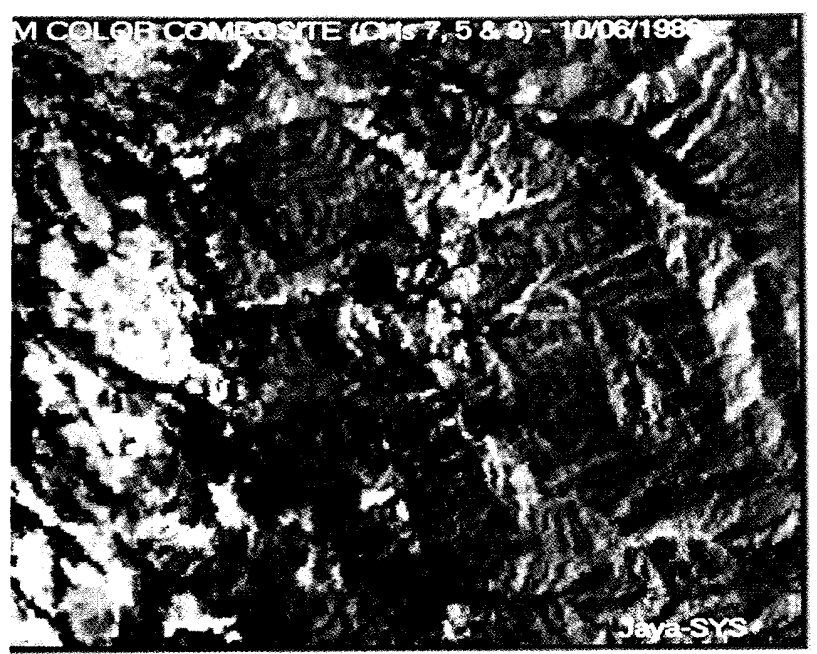

(a)

\section{STUDY SITE AND IMAGE PROCESSING}

Study Site

The main study site of the forest change detection was in Shibata, Niigata Prefecture, between latitudes $37^{\circ} 52^{\prime}$ and $37^{\circ} 58^{\prime} \mathrm{N}$ and longitudes $139^{\circ} 22^{\prime}$ and $139^{\circ} 31^{\prime} \mathrm{E}$. This area was chosen because it contains a variety of forest cover conditions such as clearcuts and various stages of growth following artificial regeneration of both Japanese cedar and pine. Further information concerning the site, singledate category description, and its classification results including the evaluation of the forest class separability can be found in our previous study (JAYA and KOBAYASHI 1995).

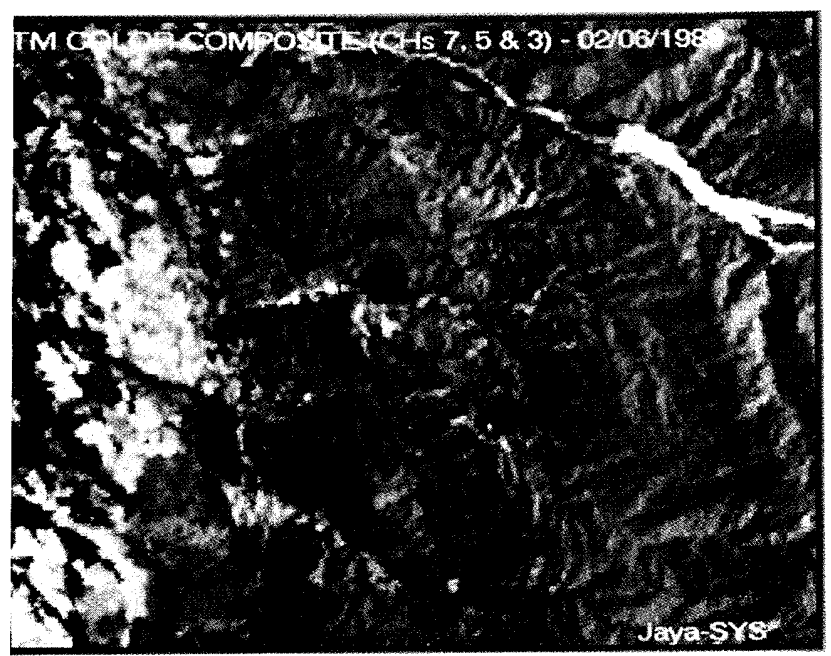

(b)

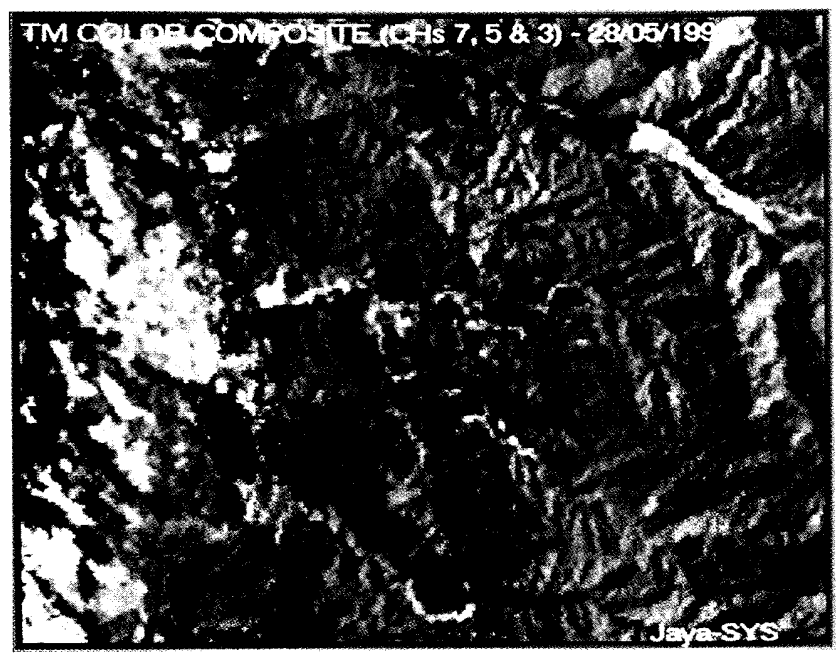

(c)

Fig. 1 Portion of the Landsat TM color composite images (band 7 as red, band 5 as green and band 3 as blue) over the study area acquired on (a) 10 June 1986, (b) 2 June 1989 and (c) 28 May 1993. The areas shown are approximately $7.3 \mathrm{~km} \times 5.7 \mathrm{~km}$. 
Image and Supporting Data

Multidate Landsat TM images acquired on 10 June 1986, 2 June 1989, and 28 May 1993 (Fig. 1) were used for analysis, assuming no atmospheric and/or phenological differences occurred between these dates. No clouds were present at each date at the time of overpass. The availability of aerial photographs obtained in 1988, 1990 and 1993, 1: 25,000 scale topographic maps, and other ancillary data, coupled with ground observation data allowed the authors to perform this change detection study. The TM 10 June 1986 data were supported by 1:20,000 forest compartment maps and forest inventory documents containing species, diameter at breast height and height information. In addition, valuable information concerning the relationship between tree height and age was obtained from the Shibata Forest Service and ground verification. An extensive effort was made to get data and information representing the actual conditions at each date through field observation, study maps and interviews.

\section{Image Processing Hardware and Software}

The so-called JAYA-SYSTEM software, which had been developed and coded using Quick-C programming language by the authors was used for the analysis. The ability to rectify, register and overlay data from different dates, to create either standardized or unstandardized principal component (PC) images, to classify them using maximum likelihood classifier, to generate image enhancements and filtering, to compute divergence and its transformation (TD) and to evaluate the significance of several confusion matrices based on Kappa statistics is an essential attribute of the software needed for this study. The mathematical concepts and terminologies that constitute the software referred to the descriptions of CONGALTON et al. (1983), JENSEN (1986), Richards (1993), and HudSON and RAMM(1987). The analysis was carried out on a personal computer of the NEC PC-9821 series.

\section{CHANGE DETECTION METHODS}

\section{Geometric Correction and Registration}

Prior to any other analysis, "image-to-map" rectification and "image-to-image" registration were conducted. The rectification of TM 02 June 1989 images followed by the registration of the remaining TM 1986 and 1989 had been done by JAYA and KOBAYASH in previous studies (1994, 1995).
Image Smoothing

The anticipated registration errors that are often compounded by the complexity of forest cover patterns and topography may cause significant overestimates of change, particularly that occurs with boundary pixels. To reduce this source of error, the images were smoothed using a $3 \times$ 3 size median filter. Many authors (e.g. CHUSNIE and AtKINSON 1985; GonZALEZ and WintZ 1988; NARENDRA 1983; and RICHARDS 1993) proved that a median filter was effective for smoothing images without blurring the sharp edges or details in the image as much as the equivalent linear low-pass filter. We also used the median filter because it does not alter the pixel brightness values during filtering.

\section{Change Detection Methods}

Of the various available change detection methods (Howarth and WickWARE 1981; and SingH 1989, we examined forest change detection using the following methods.

\section{(1) Direct multidate classification}

In this method, the two-date original TM data of the same bands were classified simultaneously using training data sets representing specific types of change and nochange. The classification was based on the multidate TM bands which consisted of the same original TM bands of different dates. This method is quite simple and requires only a single classification, but it requires many bands. Since a full band set may be redundant in information content, classification using a reduced multidate band was then examined. The input images were comprised of spatially-filtered images. This method was used as a standard to evaluate the effectiveness of the change detection techniques that will be described further.

\section{(2) Principal component}

Principal component transformation was performed as a preprocessing procedure prior to automated classification. This transformation should be able to increase computational efficiency of the classification because it may reduce the dimensionality of the original data. The purpose of using principal component analysis is to create a combination of given TM bands that generate significant dimensionality indices for detecting forest cover change. Since TM bands 3 and 4 are highly correlated with the amount of vegetation cover, the eigenvector weights and algebraic signs of these bands were examined. Theoretically, this method could lead to greater separability between two classes along the new major components. The two-date TM data were put together and then processed using standardized principal components analysis to pro- 
duce new synthetic bands. Hereafter, this technique will be called the multitemporal principal component (MPC) technique. The analysis was done using two techniques: (1) 12-dimensional MPC and (2) 2-dimensional MPC. Other applications of MPC for change detection have been examined by BYRnE et al.(1980), RichaRds(1984), FUNG and LEDREW (1988), INGEBRITSEN and LyON (1985) and JIAU (1988).

In the 12-dimensional MPC technique, two different dates of six non-thermal bands were superimposed and treated as a single data set (six-plus-six). To select the PC image that summarize unchanged and changed areas, we applied the concepts of stable greenness (SG), stable brightness (SB), delta greenness (DG) and delta brightness (DB) by examining the characteristics of the eigenvector of each component (INGEBRITSEN and LYON 1985). Finally, the selected PC images referred to as SB, SG, DB and DG were classified to delineate the areas undergoing change by means of the maximum likelihood classifier using training areas as used in the direct multidate classification method.

In the 2-dimensional MPC, two TM data sets of the same bands from different dates were put together and analyzed at one time. Furthermore, in the same way, all of the second components (PC2),i.e. six PC2s, were classified based on the maximum likelihood classifier using the same training areas used in the earlier techniques.

\section{Change Detection Category}

Forest cover change categories described in this paper were formulated based on the forest categories developed in the single date classification in our previous

Table 1 The initial "from-to" change categories of the study site of all date-pairs.

\begin{tabular}{|c|c|c|c|}
\hline \multirow{2}{*}{ "from-to" change category } & 1986 & 1986 & 1989 \\
\hline & 1989 & 1993 & 1993 \\
\hline \multicolumn{4}{|l|}{ a. Forest Area } \\
\hline (1) P3,S2/3-OC: from large size of pine (P3) or & $\mathrm{x}$ & $\mathrm{x}$ & $\mathrm{x}$ \\
\hline $\begin{array}{l}\text { J. cedar }(\mathrm{S} 2 / 3) \text { to overcuts area }(\mathrm{OC}) \text {; } \\
\text { (2) OC-S0: from overcuts area }(\mathrm{OC}) \text { to seed- } \\
\text { ling stage of pine and J. cedar }(\mathrm{S} 0) \text {; }\end{array}$ & $\mathrm{x}$ & $\mathrm{x}$ & - \\
\hline $\begin{array}{l}\text { (3) S0s-S0d: from seedling stage of J. cedar } \\
\text { whose underlayer vegetation sparsely } \\
\text { developed ( } 0 \text { s) to seedling stage whose } \\
\text { underlayer vegetation fully developed (S0 } \\
\text { d); }\end{array}$ & $\mathrm{x}$ & $\mathrm{x}$ & $\mathrm{x}$ \\
\hline $\begin{array}{l}\text { (4) } \mathrm{S} 0 \text {-S1: from seedling stage }(\mathrm{S} 0) \text { to small } \\
\text { size of J. cedar }(\mathrm{S} 1) \text {; }\end{array}$ & $\mathrm{x}$ & $\mathrm{x}$ & $\mathrm{x}$ \\
\hline (5) $\mathrm{S} 1-\mathrm{S} 2 / 3$ : from small size (S1) to medium/ & $\mathrm{x}$ & $\mathrm{x}$ & $\mathrm{x}$ \\
\hline $\begin{array}{l}\text { large size of } \mathrm{J} \text {. cedar }(\mathrm{S} 2 / 3) \text {; } \\
\text { (6) } \mathrm{P}-\mathrm{P} 2 \text { : from small size }(\mathrm{P} 1) \text { to medium size } \\
\text { of pine }(\mathrm{P} 2)\end{array}$ & $\mathrm{x}$ & $\mathrm{x}$ & $\mathrm{x}$ \\
\hline $\begin{array}{l}\text { (7) P2-P3: from medium size (P2) to large size } \\
\text { of pine (P3); }\end{array}$ & $\mathrm{x}$ & $\mathrm{x}$ & $\mathrm{x}$ \\
\hline \multicolumn{4}{|l|}{ b. Non-forest area } \\
\hline $\begin{array}{l}\text { (8) B-S: from bare land (B) to shrubby area } \\
\text { (S); }\end{array}$ & $\mathrm{x}$ & $\mathrm{x}$ & $\mathrm{x}$ \\
\hline $\begin{array}{l}\text { (9) } \mathrm{DV}-\mathrm{B} / \mathrm{C} / \mathrm{E} \text { : from dense vegetation }(\mathrm{DV}) \text { to } \\
\text { bare land }(\mathrm{B}) \text {, construction }(\mathrm{C}) \text { or exposed } \\
\text { area }(\mathrm{E}) ;\end{array}$ & $\mathrm{x}$ & $\mathrm{x}$ & $\mathrm{x}$ \\
\hline $\begin{array}{l}\text { (10) } \mathrm{PF} / \mathrm{DC}-\mathrm{B} / \mathrm{C} / \mathrm{E} \text { : from paddy field }(\mathrm{PF}) \text { or } \\
\text { dry-crop vegetation }(\mathrm{DC}) \text { to bare land }(\mathrm{B}) \text {, } \\
\text { construction }(\mathrm{C}) \text { or exposed areas }(\mathrm{E}) \text {; }\end{array}$ & $\mathrm{x}$ & $\mathrm{x}$ & $\mathrm{x}$ \\
\hline $\begin{array}{l}\text { (11) SV-DV: from sparse vegetation }(\mathrm{SV}) \text { to } \\
\text { dense vegetation }(\mathrm{DV}) \text {; }\end{array}$ & $\mathrm{x}$ & $\mathrm{x}$ & $\mathrm{x}$ \\
\hline (12) NC: no-change area & $\mathrm{x}$ & $\mathrm{x}$ & $\mathrm{x}$ \\
\hline
\end{tabular}

Note: $\mathrm{x}=$ present and $-=$ not present. Because the lack of representative pixels, the category of change from P0 to P1 was not defined. When the study undertaken, the OC-S0 change category of 1989-1993 date pair was not found. 
study (JAYA and KOBAYASHI 1995). To describe what the changes have been for a specific class from one date to another, the class is defined in a "from-to" category. Then, to show where the changes took place, the class of change is displayed in a "from-to" change detection image. In our earlier study, attempts to differentiate tree height classes, $i$. e., small, medium and large, have shown that between P1 (small size of pine) and MF (mixed forest), and between S2 (medium size of J.cedar) and S3 (large size of J.cedar) are spectrally inseparable. These categories were then merged and called the $\mathrm{P} 1$ and S2/3, respectively. Based on map analysis, aerial-photo interpretation, forest inventory documents representing actual conditions at each date, analysis of the relationship between tree height and age, and ground verification, the initial "from-to" change detection categories of all date-pairs that shown in Table 1 were created.

Training data sets representing specific types of change and no-change were then derived from the original and synthetic bands of both the selected 12-dimensional MPC images and the PC2 images of the 2-dimensional MPC. Conventionally, to facilitate in setting the change detection training area, the raw images from two different dates were simply superimposed and displayed in red and green guns. However, we found a difficulty to appreciate visually all of the change and no-change information using only two original multidate TM bands. Furthermore, since the MPC effectively summarized the 12 original TM bands in the first few components, the $\mathrm{PC}$ images representing the areas of change were then used and superimposed to select training areas. Any areas that have changed will be highlighted in one of the colors. The greater the change in tone, e.g., from dark to light, between the two dates, the more dominant one of the color (green or red) will appear on the monitor. The red and green colors reveal the locations of where the changes took place. When possible, coincident training areas were selected for all possible date-pairs, i.e., 1986-1989, 1986-1993 and 1989-1993.

\section{Accuracy Measures}

In this study, we sought to evaluate the accuracy (degree of agreement) of automatic change detection based on statistical approaches. The evaluated accuracy measures were: (1) overall accuracy, (2) producer's accuracy (omission error), (3) user's accuracy (commission error) and (4) Kappa accuracy. Because only the Kappa accuracy can take into account all cells of the confusion matrix elements, the change detection accuracies were then determined on the basis of the highest Kappa accuracy. This measure had been found to be consistent to either the user's or producer's accuracy measures (FUNG and LEDREW 1988). Detailed descriptions of these accuracy measures can be found in CONGALTon et al.(1983), and RosENFIELD and FitzPATRICK-Lins (1986), while the exact equation of the Kappa accuracy and its variance has been described by HuDSON and RAMM (1987).

Separability Analysis

To evaluate whether any types of change were significantly detected or not, individual separability analyses was performed. As indicated in our earlier study (JAYA and KOBAYASHI 1995) and by other researchers, since the Transformed Divergence (TD) provided good estimates for both the interclass separability and accuracy assessment, the TD measure was then applied. On the basis of the separability and accuracy analyses obtained above, change detection images of both 12-dimensional and 2-dimensional MPC were then created using a maximum likelihood classifier.

\section{Smoothing of the Classified Image}

The rounding-off which is associated with the computation involved in MPC technique can produce some noise in images. Because the software encodes the PC score values in an 8-bit integer format (values from 0 to 255), it's believed that the rounding of intermediate results, either up or down, can produce noise whether in the PC image or in the final classification. To filter out this noise, the final change detection map was again smoothed with a $3 \times 3$ size median filter. This smoothing should be able to reduce errors that associated with misclassification and reduce overestimation of change at one time. This filtering process can eliminate small size and scattered areas of change. A flowchart of the general change detection procedure used in this study is depicted in Fig. 2.

\section{RESULTS AND DISCUSSION}

\section{Direct Multidate Classification}

The Kappa and overall accuracies of classifying both the original and the merged categories using direct multidate classification (DMC) are listed in Table 2. We can see that the change detection using only six raw TM bands, which consisted of two bands $3 \mathrm{~s}$, two bands $4 \mathrm{~s}$ and two bands $5 \mathrm{~s}$ from two different dates produced optimal results. Statistically, it appears that their Kappa values have no significant difference with the Kappa values derived from a higher number of multidate bands. That's why the change detection image based on the DMC method was then created using this combination. This shows that the full multidate band sets ( 12 bands) can be reduced without any significant reduction in accuracy. This in turn increases classification speed. 


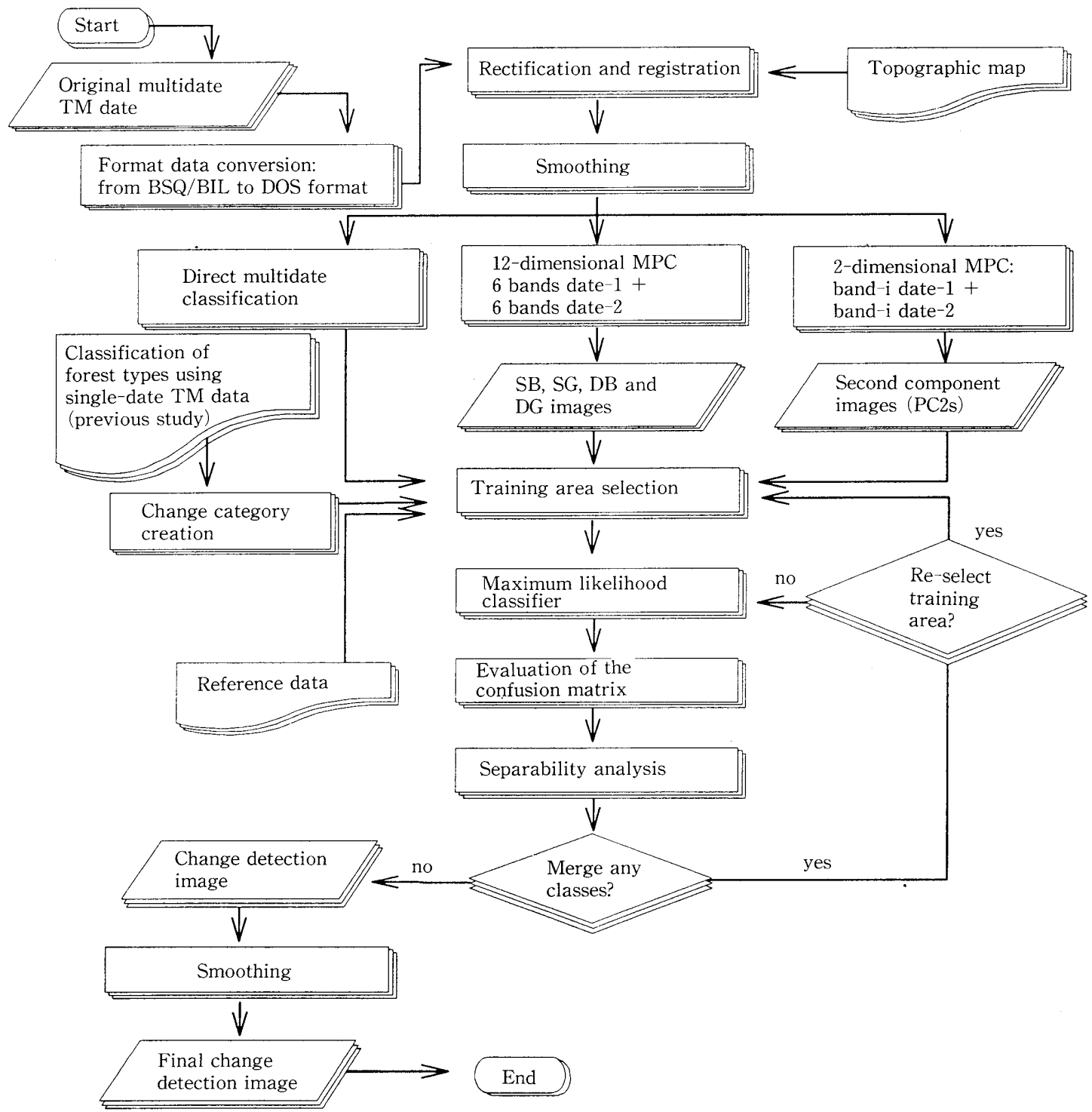

Fig. 2 Flow-chart of the change detection taken in this study.

(1) The forest change from 10 June 1986 to 2 June 1989

The evaluation of the original "from-to" change categories as determined using the transformed divergence and confusion matrix for the merged TM 10 June 1986 and TM 2 June 1989 (hereafter referred to as the 1986-1989 datepair) showed that the OC-S0, S0s-S0d and S0-S1 categories are poorly separated from each other, while the S1-S2/3, P1-P2 and P2-P3 change categories were statistically inseparable from the no-change category. In the initial confusion matrix examined, the last three change categories mentioned above produced substantial confusion with the no-change category. The results from this classification attempt clearly showed that natural growth from S1 to $\mathrm{S} 2 / 3$, from $\mathrm{P} 1$ to $\mathrm{P} 2$ and from $\mathrm{P} 2$ to $\mathrm{P} 3$ was difficult to be detected during this 3 -year period. In the final classifica- tion, using six multidate TM bands which consisted of two band $3 \mathrm{~s}$, two band $4 \mathrm{~s}$ and two band $5 \mathrm{~s}$, these categories were then merged into a no-change category producing considerably high overall accuracy, i.e. $94.4 \%$ (Table 2). Also during this 3-year period, both the producer's and user's accuracies of the change and no-change categories were encouraging, ranging from $82.7 \%$ to $100 \%$ (Table $3 a$ ). Unmelted and wet snow that still covered part of the top of Mt. Ninouji caused some problems in forest change detection.

(2) The forest change from 10 June 1986 to 28 May 1993 Between 10 June 1986 and 28 May 1993 (1986-1993 date-pair), both the changes from forested area to clearcut area (P3,S2/3-OC) and from clearcut area to new artificial 
Table 2 The Kappa and overall accuracies of change detection using direct multidate classification

\begin{tabular}{|c|c|c|c|c|c|c|c|c|c|c|c|}
\hline \multirow{3}{*}{$\begin{array}{l}\text { Number } \\
\text { of band }\end{array}$} & \multirow{3}{*}{\multicolumn{4}{|c|}{$\begin{array}{l}\text { multidate of } \\
\text { TM band }\end{array}$}} & & \multicolumn{3}{|c|}{ Original category } & \multicolumn{3}{|c|}{ Merged category } \\
\hline & & & & & & \multicolumn{3}{|c|}{ Accuracy } & \multicolumn{3}{|c|}{ Accuracy } \\
\hline & & & & & & Kappa & Overall & TDavg & Kappa & Overall & TDavg \\
\hline & from & 10 & June & e 19 & 86 to 2 & June 1989 & & & & & \\
\hline 12 & 1 & 2 & 3 & 4 & 57 & 67.71 & 70.70 & 2000.0 & 97.02 & 97.72 & 2000.0 \\
\hline 10 & 1 & 2 & 3 & 4 & 5 & 66.46 & 69.52 & 1999.3 & 94.40 & 96.48 & 2000.0 \\
\hline 8 & 2 & 3 & 4 & 5 & & 65.55 & 68.90 & 1997.4 & 94.96 & 96.13 & 2000.0 \\
\hline 6 & 3 & 4 & 5 & & & 61.57 & 65.03 & 1995.9 & 94.42 & 95.72 & 2000.0 \\
\hline \multirow[t]{2}{*}{4} & 3 & 4 & & & & 53.31 & 60.60 & 1990.0 & 85.82 & 89.01 & 1999.9 \\
\hline & from & 10 & June & e 19 & 86 to 28 & 3 May 1993 & & & & & \\
\hline 12 & 1 & 2 & 3 & 4 & $5 \quad 7$ & 70.92 & 73.79 & 2000.0 & 90.18 & 92.40 & 2000.0 \\
\hline 10 & 1 & 2 & 3 & 4 & 5 & 69.99 & 72.87 & 1999.8 & 90.40 & 92.57 & 1999.5 \\
\hline 8 & 2 & 3 & 4 & 5 & & 64.03 & 67.03 & 1999.4 & 89.88 & 92.15 & 1998.9 \\
\hline 6 & 3 & 4 & 5 & & & 62.96 & 66.03 & 1998.8 & 90.63 & 92.74 & 1997.8 \\
\hline \multirow[t]{2}{*}{4} & 3 & 4 & & & & 56.87 & 60.60 & 1993.0 & 78.46 & 83.39 & 1985.4 \\
\hline & from & $2 J$ & une & 198 & 9 to 28 & May 1993 & & & & & \\
\hline 12 & 1 & 2 & 3 & 4 & $5 \quad 7$ & 72.88 & 78.67 & 2000.0 & 94.30 & 96.22 & 2000.0 \\
\hline 10 & 2 & 3 & 4 & 5 & 7 & 67.10 & 73.49 & 2000.0 & 94.95 & 96.66 & 2000.0 \\
\hline 8 & 2 & 3 & 4 & 5 & & 61.40 & 67.78 & 1997.4 & 94.96 & 96.66 & 2000.0 \\
\hline 6 & 3 & 4 & 5 & & & 57.93 & 64.18 & 1993.4 & 93.66 & 95.79 & 1991.1 \\
\hline 4 & 3 & 4 & & & & 54.67 & 61.55 & 1982.3 & 83.38 & 90.25 & 1996.4 \\
\hline
\end{tabular}

Note: The vertical lines that connect the Kappa values express that those values are not significantly different at $95 \%$ confidence level.

regeneration (OC-S0) were accurately detected. By examining the final confusion matrix (Table $3 \mathrm{~b}$ ), we can see that S0s-S0d exhibits little confusion with the S0-S1 category, producing only $76.4 \%$ and $70 \%$ user's accuracy. Based on ground observations, and studies of maps, aerialphoto interpretations, and forest inventory documents, some areas of S0 (defined in TM 10 June 1986) were approaching the $\mathrm{S} 1$ category and had been densely invaded by shrub vegetation. During this 7-year period, the S0 category had developed considerably into the S1 category, so the accuracy of the change detection from the seedling stage of $\mathrm{J}$. cedar to the medium size of $\mathrm{J}$. cedar ( $\mathrm{S} 0-\mathrm{S} 1$ ) was encouraging. The confusion between the change from S0 whose understory vegetation sparsely developed to S0 whose understory had fully developed (S0s-S0d) with S0-S1 may be related to the fact that the changes in reflectance due to tree height growth and the invasion of shrub vegetation produced similar delta greenness. Actually, the ground condition of the Sod was at any point within the development sequence between S0 and S1 categories. These facts were supported by the results obtained by RICHARDSON and WIEGAND 1977, and TUCKER and MAXWELL 1976 in which reflectance of red and near-infrared (TM bands 3 and 4) were correlated closely with plant height and vegetation density.

During this period, cutting activity within the forest bounds (P3,S2/3-OC) is difficult to be distinguished from the transformation from paddy or dry-crop fields to barren land/construction/exposed area $(\mathrm{PF} / \mathrm{DC}-\mathrm{B} / \mathrm{C} / \mathrm{E})$, producing only $72.7 \%$ user's accuracy. The changes due to new artificial regeneration (OC-S0) were clearly identified. As a result of the separability. analysis and examination of the confusion matrix, the changes from $\mathrm{S} 1$ to $\mathrm{S} 2 / 3, \mathrm{P} 1$ to $\mathrm{P} 2$, and $\mathrm{P} 2$ to $\mathrm{P} 3$ during this 7 -year period, could not be detected because of their similarity to the no-change category. Therefore, these types of changes were finally grouped into the no-change category.

(3) The forest change from 10 June 1989 to 28 May 1993

During this period, there were the same difficulties in distinguishing between S0s-S0d and S0-S1 as occurred in the 1986-1989 date-pair. However, during this 4-year period, the changes due to harvesting activities (P3, S2/3-OC), agricultural land conversion (B-S, PF/DC-B/C/E, DV-B/ $\mathrm{C} / \mathrm{E}$ ) and SV-DV were considerably detected, as indicated by both the producer's and user's accuracies that fell between $83.1 \%$ and $100 \%$ (Table 3c). The changes detected in the dry crop fields, might have been due to differences in water content (and thus soil background reflectance) between the two dates, differences in seasonal crop types, or conversion from cropped area to harvested area. The changes that were detected in agricultural areas might be the norm as farmers practice crop rotation, e.g., change crop types, fallow periods etc.). Urban areas that consisted of various small-size features such as paved areas, residential roofs, area with scattered trees or woods, were poten- 
Table 3 Confusion matrix of the final change detection category based on direct multidate classification using six multidate TM bands that consisted of two band 3s, two band $4 \mathrm{~s}$ and two band $5 \mathrm{~s}$.

(a) from 10 June 1986 to 2 June 1989

\begin{tabular}{crrrrrrrrr}
\hline \multicolumn{2}{c}{$\begin{array}{c}\text { Class } \\
\text { Number } \\
\text { of pixel }\end{array}$} & C1 & C2 & C3 & C4 & C5 & C6 & C7 & $\begin{array}{c}\text { Producer's } \\
\text { accuracy }\end{array}$ \\
\hline C1 & 132 & 126 & 0 & 0 & 6 & 0 & 0 & 0 & 95.45 \\
C2 & 294 & 0 & 293 & 0 & 0 & 0 & 0 & 1 & 99.66 \\
C3 & 97 & 0 & 0 & 94 & 0 & 0 & 3 & 0 & 96.91 \\
C4 & 81 & 11 & 0 & 2 & 67 & 0 & 0 & 1 & 82.72 \\
C5 & 121 & 0 & 5 & 0 & 0 & 116 & 0 & 0 & 95.87 \\
C6 & 139 & 0 & 0 & 0 & 0 & 0 & 139 & 0 & 100.00 \\
C7 & 583 & 0 & 33 & 0 & 0 & 0 & 0 & 550 & 94.34 \\
\hline User's accuracy & 92.0 & 88.5 & 97.9 & 91.8 & 100.0 & 97.9 & 99.6 & \\
\hline
\end{tabular}

Change categories: $\mathrm{C} 1: \mathrm{P} 3, \mathrm{~S} 2 / 3-\mathrm{OC} ; \mathrm{C} 2: \mathrm{OC}-\mathrm{S} 0 / \mathrm{S} 0 \mathrm{~s}-\mathrm{S} 0 \mathrm{~d} / \mathrm{S} 0-\mathrm{S} 1 ; \mathrm{C} 3: \mathrm{B}-\mathrm{S} ; \mathrm{C} 4: \mathrm{PF} / \mathrm{DC}-\mathrm{B} / \mathrm{C} / \mathrm{E}$;C5:SV-DV; $\mathrm{C} 6: \mathrm{DV}-\mathrm{B} / \mathrm{C} / \mathrm{E}$; and $\mathrm{C} 7: \mathrm{NC}$

(b) from 10 June 1986 to 28 May 1993

\begin{tabular}{ccrrrrrrrrc}
\hline \multicolumn{2}{c}{$\begin{array}{c}\text { Class Number } \\
\text { of pixel }\end{array}$} & C1 & C2 & C3 & C4 & C5 & C6 & C7 & C8 & $\begin{array}{l}\text { Producer's } \\
\text { accuracy }\end{array}$ \\
\hline C1 & 97 & 96 & 0 & 0 & 0 & 0 & 0 & 0 & 1 & 98.97 \\
C2 & 91 & 0 & 73 & 18 & 0 & 0 & 0 & 0 & 0 & 80.22 \\
C3 & 56 & 0 & 6 & 50 & 0 & 0 & 0 & 0 & 0 & 89.29 \\
C4 & 50 & 0 & 1 & 0 & 49 & 0 & 0 & 0 & 0 & 98.00 \\
C5 & 99 & 0 & 0 & 0 & 1 & 98 & 0 & 0 & 0 & 98.99 \\
C6 & 204 & 36 & 3 & 1 & 0 & 0 & 161 & 0 & 3 & 78.92 \\
C7 & 109 & 0 & 7 & 2 & 2 & 0 & 0 & 98 & 0 & 89.91 \\
C8 & 492 & 0 & 6 & 0 & 0 & 0 & 0 & 0 & 486 & 98.78 \\
\hline User's accuracy & 72.7 & 76.0 & 70.4 & 94.2 & 100.0 & 100.0 & 100.0 & 99.2 &
\end{tabular}

Change categories: C1:P3,S2/3-OC; C2:S0s-S0d; C3:S0-S1; C4:OC-S0; C5:B-S; C6:PF/DC-B/C/E; C7:SV$\mathrm{DV}$; and $\mathrm{C} 8 \mathrm{NC}$.

(C) from 2 June 1989 to 28 May 1993

\begin{tabular}{|c|c|c|c|c|c|c|c|c|c|}
\hline Class & $\begin{array}{l}\text { Number } \\
\text { of pixel }\end{array}$ & $\mathrm{C} 1$ & $\mathrm{C} 2$ & $\mathrm{C} 3$ & $\mathrm{C} 4$ & $\mathrm{C} 5$ & C6 & $\mathrm{C} 7$ & $\begin{array}{l}\text { Producer's } \\
\text { accuracy }\end{array}$ \\
\hline $\mathrm{C} 1$ & 25 & 25 & 0 & 0 & 0 & 0 & 0 & 0 & 100.00 \\
\hline $\mathrm{C} 2$ & 123 & 0 & 118 & 0 & 0 & 0 & 0 & 5 & 95.38 \\
\hline $\mathrm{C} 3$ & 69 & 0 & 0 & 69 & 0 & 0 & 0 & 0 & 100.00 \\
\hline $\mathrm{C} 4$ & 50 & 2 & 0 & 0 & 43 & 0 & 5 & 0 & 86.00 \\
\hline $\mathrm{C} 5$ & 102 & 0 & 0 & 3 & 0 & 99 & 0 & 0 & 97.06 \\
\hline $\mathrm{C} 6$ & 141 & 0 & 0 & 0 & 0 & 1 & 140 & 0 & 99.29 \\
\hline $\mathrm{C} 7$ & 629 & 0 & 24 & 8 & 0 & 0 & 0 & 597 & 94.91 \\
\hline
\end{tabular}

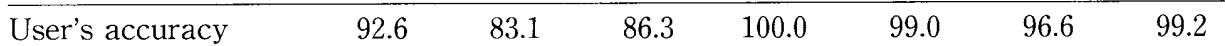

Change categories: $\mathrm{C} 1: \mathrm{P} 3, \mathrm{~S} 2 / 3-\mathrm{OC} ; \mathrm{C} 2: \mathrm{S} 0 \mathrm{~s}-\mathrm{S} 0 \mathrm{~d} / \mathrm{S} 0-\mathrm{S} 1 ; \mathrm{C} 3: \mathrm{B}-\mathrm{S} ; \mathrm{C} 4: \mathrm{PF} / \mathrm{DC}-\mathrm{B} / \mathrm{C} / \mathrm{E} ; \mathrm{C} 5: \mathrm{SV}-\mathrm{DV}$; C6:DV$\mathrm{B} / \mathrm{C} / \mathrm{E}$; and $\mathrm{C} 7 \mathrm{NC}$ 
Table 4 Eigenvector patterns of the first five 12-dimensional MPCs

(a) Merged TM 10 June 1986 and 2 June 1989

\begin{tabular}{lcccccc}
\hline Year & Band & PC1 & PC2 & PC3 & PC4 & \multicolumn{1}{c}{ PC5 } \\
\hline TM 10 & 1 & 0.30749 & -0.25662 & -0.12274 & -0.16762 & -0.10008 \\
June & 2 & 0.29685 & -0.29132 & -0.15947 & -0.32602 & 0.14992 \\
1986 & 3 & 0.26341 & -0.37757 & -0.08312 & -0.42188 & 0.28992 \\
& 4 & 0.28166 & 0.26959 & -0.48335 & -0.09779 & -0.05393 \\
& 5 & 0.27187 & 0.37989 & -0.02482 & -0.19859 & -0.36333 \\
TM 2 & 7 & 0.28364 & 0.25234 & 0.37916 & -0.37526 & -0.43441 \\
June & 1 & 0.31071 & -0.17846 & 0.03390 & 0.47885 & -0.35069 \\
1989 & 2 & 0.31732 & -0.20304 & 0.02725 & 0.35730 & -0.13950 \\
& 3 & 0.28448 & -0.33520 & 0.01536 & 0.22795 & -0.02891 \\
& 4 & 0.27029 & 0.31093 & -0.43304 & 0.26466 & 0.26185 \\
& 5 & 0.28572 & 0.33976 & 0.09473 & 0.13133 & 0.39203 \\
Eigenvalue: & 7 & 0.28530 & 0.16884 & 0.59380 & 0.03981 & 0.44078 \\
Proportion: & 8.4859 & 2.2964 & 0.5812 & 0.3441 & 0.1577 \\
Cumulative: & 70.72 & 19.14 & 4.84 & 2.87 & 1.31 \\
Description: & 70.72 & 89.85 & 94.70 & 97.56 & 98.88 \\
& stable & stable & - & delta & delta \\
\hline
\end{tabular}

(b) Merged TM 10 June 1986 and 28 May 1993

\begin{tabular}{|c|c|c|c|c|c|c|}
\hline Year & Band & $\mathrm{PCl}$ & $\mathrm{PC} 2$ & PC3 & PC4 & PC5 \\
\hline TM 10 & 1 & 0.32104 & -0.20363 & 0.00676 & -0.21257 & 0.31425 \\
\hline June & 2 & 0.31540 & -0.24504 & -0.00223 & -0.21492 & 0.35359 \\
\hline \multirow[t]{4}{*}{1986} & 3 & 0.28536 & -0.32620 & 0.08564 & -0.17179 & 0.38317 \\
\hline & 4 & 0.28719 & 0.24112 & -0.46674 & -0.27706 & -0.00091 \\
\hline & 5 & 0.26928 & 0.36133 & -0.03950 & -0.36105 & -0.26297 \\
\hline & 7 & 0.28167 & 0.26396 & 0.39484 & -0.39794 & -0.33614 \\
\hline TM 28 & 1 & 0.31678 & -0.23049 & -0.01605 & 0.21170 & -0.28733 \\
\hline May & 2 & 0.31546 & -0.24538 & -0.04882 & 0.24185 & -0.30667 \\
\hline \multirow[t]{4}{*}{1993} & 3 & 0.28070 & -0.33777 & 0.06616 & 0.20531 & -0.38492 \\
\hline & 4 & 0.27817 & 0.23744 & -0.53255 & 0.34808 & 0.07118 \\
\hline & 5 & 0.24538 & 0.40780 & 0.04863 & 0.35338 & 0.27255 \\
\hline & 7 & 0.25583 & 0.28912 & 0.56948 & 0.34948 & 0.20771 \\
\hline \multicolumn{2}{|c|}{ Eigenvalue: } & 8.0275 & 2.7756 & 0.5839 & 0.3008 & 0.1386 \\
\hline \multicolumn{2}{|c|}{ Proportion: } & 66.90 & 23.13 & 4.87 & 2.51 & 1.16 \\
\hline \multicolumn{2}{|c|}{ Cumulative: } & 66.90 & 90.03 & 94.89 & 97.40 & 98.55 \\
\hline \multicolumn{2}{|c|}{ Description: } & $\begin{array}{l}\text { stable } \\
\text { brightness }\end{array}$ & $\begin{array}{l}\text { stable } \\
\text { greenness }\end{array}$ & $\begin{array}{l}\text { stable } \\
\text { greenness }\end{array}$ & $\begin{array}{l}\text { delta } \\
\text { brightness }\end{array}$ & $\begin{array}{l}\text { delta } \\
\text { greenness }\end{array}$ \\
\hline \multicolumn{7}{|c|}{ (c) Merged TM 2 June 1989 and 28 May 1993} \\
\hline Year & Band & PC1 & PC2 & PC3 & PC4 & PC5 \\
\hline TM 2 & 1 & 0.31703 & -0.16119 & 0.03086 & -0.50386 & 0.25901 \\
\hline June & 2 & 0.32334 & -0.18943 & 0.03464 & -0.37731 & 0.11341 \\
\hline \multirow[t]{4}{*}{1986} & 3 & 0.29161 & -0.31359 & 0.16324 & -0.24355 & 0.10969 \\
\hline & 4 & 0.27245 & 0.28947 & -0.44880 & -0.19782 & -0.26685 \\
\hline & 5 & 0.28917 & 0.33052 & 0.01637 & -0.08973 & -0.45549 \\
\hline & 7 & 0.29130 & 0.17975 & 0.48587 & -0.02247 & -0.48674 \\
\hline TM 28 & 1 & 0.30756 & -0.27815 & -0.09833 & 0.18595 & 0.02404 \\
\hline May & 2 & 0.30220 & -0.28564 & -0.13842 & 0.33157 & -0.06815 \\
\hline \multirow[t]{4}{*}{1993} & 3 & 0.26291 & -0.37885 & -0.04111 & 0.46373 & -0.19575 \\
\hline & 4 & 0.27636 & 0.24502 & -0.52045 & 0.14503 & 0.20536 \\
\hline & 5 & 0.25508 & 0.41638 & 0.02424 & 0.15082 & 0.41571 \\
\hline & 7 & 0.26594 & 0.28030 & 0.48111 & 0.30565 & 0.36591 \\
\hline \multicolumn{2}{|c|}{ Eigenvalue: } & 8.216 & 2.4032 & 0.6873 & 0.3392 & 0.2028 \\
\hline \multicolumn{2}{|c|}{ Proportion: } & 68.47 & 20.03 & 5.73 & 2.83 & 1.69 \\
\hline \multicolumn{2}{|c|}{ Cumulative: } & 68.47 & 88.49 & 94.22 & 97.05 & 98.74 \\
\hline \multicolumn{2}{|c|}{ Description: } & $\begin{array}{l}\text { stable } \\
\text { brightness }\end{array}$ & $\begin{array}{l}\text { stable } \\
\text { greenness }\end{array}$ & - & $\begin{array}{l}\text { delta } \\
\text { brightness }\end{array}$ & $\begin{array}{l}\text { delta } \\
\text { greenness }\end{array}$ \\
\hline
\end{tabular}

Source: JAYA and KOBAYASHI (1994) 
tial sources of much confusion. As mentioned earlier, the registration errors that are often compounded by the complexity of land cover patterns may cause overestimation of change.

\section{Multitemporal Principal Component}

\section{(1) 12-dimensional MPC}

Table 4 summarizes the eigenvectors of the first five components of all date-pairs derived by JAYA and KOBAYA SHI (1994) when they carried out a qualitative evaluation of the MPC images. Here we were tempted to create a change detection map using automated classification. This automated approach was based solely on reflectance (i.e. digital number) range and ignored the basic diagnostic interpretation elements such as tone/color, shape, size, texture, shadow, pattern, location and association of the objects that are usually used in visual image analysis. As indicated by the proportion of their eigenvalues, the first five components accounted for $98.9 \%, 98.6 \%$ and $98.7 \%$ of the total variance for 1986-1989, 1986-1993 and 1989-1993 date-pairs, respectively, while the rest accounted for only less than 1.5\%. In addition, the eigenvector characteristics of the remaining last seven components did not show any specific pattern that would be useful for forest change detection. Therefor, the discussion and analysis were focused within these components. As shown, the eigenvector loadings of the first principal components $(\mathrm{PCls})$ are all positive and very similar in magnitude, indicating a stable brightness (SB) component. In the PC2 image the changed areas were not readily apparent. Its eigenvector loadings express the stable greenness (SG) where the visible bands are always negatively loaded, while near- and mid-infrared bands are positively loaded in both earlier and latter dates. This PC2 characteristic closely matches the theoretical spectral response of vegetation as mentioned earlier. As indicated by its eigenvector, particularly, bands 3 and 4, the PC3 of the 1986-1993 date-pair also summarizes the stable greenness, however, the PC3s of the other date-pairs do not explain any specific feature. The PC4s obviously represent change in brightness (delta brightness/DB) where the eigenvector loadings are always negative on the data from earlier date but positive on the data from the other date counterpart. The fifth component (PC5) images for all date-pairs measured the change in greenness (delta greenness/DG) as indicated by their eigenvector characteristics that are always positively loaded in the visible bands (except band 1) and negatively loaded in the near-and mid-infrared (bands 4, 5 and 7) from the earlier date and inverted sign in the latter date. In these components any forest covers with an increase in greenness were bright, while those where the greenness decrease were dark.

Summarizing all of the above, the SB, SG, DB and DG for all date-pairs were mapped consistently within the first five components, i.e. in the first (PC1), second ( $\mathrm{PC} 2)$, fourth (PC4) and fifth (PC5) components, respectively. Particularly for 1986-1993 date-pair, the SG was also mapped in third components (Table 4b). This may depend on the nature of change between dates. These components appear to be useful for both qualitative and quantitative analyses. JAYA and KOBAYASHI (1994) made some trial and error to superimpose three or two of the selected components for visual interpretation. They found that the principal component images representing the change are more interpretable than the original data. The color composite images created using the $\mathrm{PC}$ images representing the change of interest depicted the areas of change in unique color tones which were easier to interpret than the individual black-and-white images. As with the quantitative change detection carried out here, the automated classification appears to discriminate the areas of change clearly than that could be obtained from visual interpretation.

\section{(2) 2-dimensional MPC}

Table 5 clearly shows that the magnitude and sign of the eigenvector loading values of second components from one date is perfectly inverted from the other date counterpart (Table 5). As expected, the second components of the 2-dimensional MPC picked up the change of interest. Furthermore, the change detection image using an optimal combination of all possible $\mathrm{PC} 2$ combination was performed. The composite image formed by displaying three of the six second components of these 2-dimensional images also highlighted the forest cover changes of interest. These results agree with the study results obtained by RICHARDS (1984).

\section{Forest Cover Change Accuracy}

Instead of using multidate original TM bands, the synthetic bands referred to as stable-brightness, deltabrightness and delta-greenness obtained previously were applied. Using the same way and the same categories, the produced Kappa and overall accuracies using the 12dimensional and 2-dimensional MPC techniques are listed in Table 6. These methods also identified the same separable and inseparable class-pairs as were identified using direct multidate classification. This table clearly shows that inclusion of the SB, SG, DB and DG images in classifying the original categories always gave the highest rank of both overall and Kappa accuracies. A similar tendency was also seen when classifying the merged categories. As depicted, the accuracies using only the DB and DG components are ranked in the lower order. Exclusion of SB and SG caused loss of no-change information (static cover change). In other words, this study suggests that due to the characteristics of their eigenvector loadings, the SB, SG, 
Table 5 Engenvectors of the two-dimesional multitemporal principal component

\begin{tabular}{|c|c|c|c|c|c|c|c|c|c|}
\hline \multirow[b]{2}{*}{ Band } & \multicolumn{3}{|c|}{$\begin{array}{l}\text { TM } 10 \text { June } 1986 \text { and } \\
\text { TM } 2 \text { June } 1989\end{array}$} & \multicolumn{3}{|c|}{$\begin{array}{l}\text { TM } 10 \text { June } 1986 \text { and } \\
\text { TM } 28 \text { May } 1993\end{array}$} & \multicolumn{3}{|c|}{$\begin{array}{l}\text { TM } 2 \text { June } 1989 \text { and } \\
\text { TM } 28 \text { May } 1993\end{array}$} \\
\hline & Year & PC1 & $\mathrm{PC} 2$ & Year & $\mathrm{PC} 1$ & $\mathrm{PC} 2$ & Year & $\mathrm{PC} 1$ & $\mathrm{PC} 2$ \\
\hline 1 & 1986 & 0.7071 & 0.7071 & 1986 & 0.7071 & 0.7071 & 1989 & 0.7071 & 0.7071 \\
\hline 1 & 1989 & 0.7071 & -0.7071 & 1993 & 0.7071 & -0.7071 & 1993 & 0.7071 & -0.7071 \\
\hline \multicolumn{2}{|c|}{ Proportion } & 95.06 & 4.94 & & 97.08 & 2.92 & & 94.36 & 5.64 \\
\hline 2 & 1986 & 0.7071 & -0.7071 & 1986 & 0.7071 & 0.7071 & 1989 & 0.7071 & 0.7071 \\
\hline 2 & 1989 & 0.7071 & 0.7071 & 1993 & 0.7071 & -0.7071 & 1993 & 0.7071 & -0.7071 \\
\hline \multicolumn{2}{|c|}{ Proportion } & 94.49 & 5.51 & & 96.79 & 3.21 & & 94.28 & 5.72 \\
\hline 3 & 1986 & 0.7071 & 0.7071 & 1986 & 0.7071 & 0.7071 & 1989 & 0.7071 & -0.7071 \\
\hline 3 & 1989 & 0.7071 & -0.7071 & 1993 & 0.7071 & -0.7071 & 1993 & 0.7071 & 0.7071 \\
\hline \multicolumn{2}{|c|}{ Proportion } & 94.38 & 5.62 & & 96.53 & 3.47 & & 93.64 & 6.36 \\
\hline 4 & 1986 & 0.7071 & 0.7071 & 1986 & 0.7071 & 0.7071 & 1989 & 0.7071 & 0.7071 \\
\hline 4 & 1989 & 0.7071 & -0.7071 & 1993 & 0.7071 & -0.7071 & 1993 & 0.7071 & -0.7071 \\
\hline \multicolumn{2}{|c|}{ Proportion } & 96.79 & 3.21 & & 94.90 & 5.10 & & 95.44 & 4.56 \\
\hline 5 & 1986 & 0.7071 & 0.7071 & 1986 & 0.7071 & 0.7071 & 1989 & 0.7071 & 0.7071 \\
\hline 5 & 1989 & 0.7071 & -0.7071 & 1993 & 0.7071 & -0.7071 & 1993 & 0.7071 & -0.7071 \\
\hline \multicolumn{2}{|c|}{ Proportion } & 96.14 & 3.86 & & 94.56 & 5.44 & & 94.75 & 5.25 \\
\hline 7 & 1986 & 0.7071 & 0.7071 & 1986 & 0.7071 & 0.7071 & 1989 & 0.7071 & 0.7071 \\
\hline 7 & 1989 & 0.7071 & -0.7071 & 1993 & 0.7071 & -0.7071 & 1993 & 0.7071 & -0.7071 \\
\hline \multicolumn{2}{|c|}{ Proportion } & 93.70 & 6.30 & & 93.02 & 6.98 & & 93.45 & 6.55 \\
\hline
\end{tabular}

Source: JAYA and KOBAYASHI (1994)

DB and DG must be included in the change detection using the 12-dimensional MPC technique.

In comparison with the accuracies of the 2 dimensional MPC, change detection accuracies produced using the SB, SG, DB and DG are higher than the accuracies produced using all six of the 2-dimensional MPC images. In addition, the 12-dimensional MPC provided better delineation of forest cover change than that produced using 2-dimensional MPC. The final confusion matrices of 12-dimensional MPC are shown in Table 7.

Comparing the accuracy of the three change detection techniques examined here, we see that except for the 19891993 date pair, both the DMC using 6 multidate bands and the 12-dimensional MPC using SB, SG, DB and DG (Table 4) provided very close Kappa accuracy, i.e., $94.4 \%$ and $94.2 \%$ for the 1986-1989 date pair, and $90.6 \%$ and $90.8 \%$ for the 1986-1993 date pair (see Tables 2 and 6). Unfortunately, for the 1989-1993 date pair, the change detection map derived using the 12-dimensional MPC (map is not displayed here) appears to overestimate the areas of forest cover change. The change detection image using direct multidate classification provided better accuracy. The overestimates of change assessed by MPC technique might have been greatly affected by the large part of the area that was covered by unmelted and wet snow indicating change. According to RICHARDS (1984), this MPC technique would be useful when the area includes a substantial area of relatively no-change, Final change detection maps created for all date pairs are depicted in Fig. 3. The 1986-1989 and 1986-1993 date pairs were created using 12-dimensional, while the 1989-1993 date pair was created using the DMC technique (Fig. 3c).

In this study site, a particular finding was the changes in the young forest plantation within the forest service territory, on the center of the image. These forest plantation changes are revegetations from the 1986 or from earlier date. In general, the DMC method provided consistent better results in delineating forest cover change. This indicates that the original pixel values contain an important information of forest change. The combination of red, near infra-red and middle infra-red bands makes all the difference when discriminating one type of change versus another.

From the dimensionality standpoint, using only SB, SG, DB and DG could effectively reduce number of bands and provide considerably close accuracy with the DMC technique. However, this gain in efficiency comes with a little loss in accuracy. This shows that 12-dimensional MPC 
Table 6 The Kappa and overall accuracies of change detection using multitemporal principal component technique

\begin{tabular}{|c|c|c|c|c|c|c|}
\hline Synthetic bands & $\begin{array}{l}\text { Original } \\
\text { Kappa }\end{array}$ & $\begin{array}{l}\text { category } \\
\text { Accuracy } \\
\text { Overall }\end{array}$ & TDavg & Merged & $\begin{array}{l}\text { category } \\
\text { Accruacy } \\
\text { Overall }\end{array}$ & TDavg \\
\hline \multicolumn{7}{|c|}{ (a) from 10 June 1986 to 2 June 1989} \\
\hline \multicolumn{7}{|c|}{ 12-dimensional $M P C$} \\
\hline PC1,PC2,PC3,PC4 \&PC5 & 62.1 & 65.2 & 1990.9 & 93.8 & 95.3 & 2000.0 \\
\hline PC1,PC2,PC4 \& PC5 & 64.5 & 65.3 & 1982.0 & 94.2 & 95.3 & 1999.9 \\
\hline PC4 \& PC5 & 56.0 & 59.2 & 1854.9 & 92.9 & 94.5 & 1926.9 \\
\hline \multicolumn{7}{|l|}{ 2-dimensional $M P C$} \\
\hline $\mathrm{PC} 2$ of $\mathrm{CHs} 1,2,3,4,5 \& 7$ & 60.0 & 63.8 & 1954.5 & 83.9 & 87.8 & 1981.2 \\
\hline PC2 of CHs $1,2,3,4 \& 7$ & 57.7 & 61.4 & 1940.2 & 84.0 & 87.8 & 1965.8 \\
\hline PC2 of $\mathrm{CHs} 2,3,4 \& 7$ & 52.9 & 56.7 & 1917.7 & 85.1 & 88.1 & 1963.6 \\
\hline $\mathrm{PC} 2$ of $\mathrm{CHs} 3,4 \& 7$ & 53.5 & 57.4 & 1890.4 & 84.9 & 88.7 & 1957.1 \\
\hline $\mathrm{PC} 2$ of $\mathrm{CHs} 3 \& 4$ & 40.4 & 44.6 & 1821.3 & 62.0 & 70.5 & 1852.3 \\
\hline \multirow{2}{*}{\multicolumn{7}{|c|}{$\begin{array}{l}\text { (b) from } 10 \text { June } 1986 \text { to } 28 \text { May } 1993 \\
\text { 12-dimensional MPC }\end{array}$}} \\
\hline & & & & & & \\
\hline PC1,PC2,PC3,PC4 \& PC5 & 60.5 & 63.4 & 1996.6 & 90.8 & 92.9 & 1995.3 \\
\hline PC1,PC2,PC4 \& PC5 & 57.5 & 60.7 & 1984.4 & 82.8 & 86.5 & 1973.3 \\
\hline PC4 \& PC5 & 51.6 & 56.9 & 1794.3 & 67.8 & 74.4 & 1826.2 \\
\hline \multicolumn{7}{|l|}{ 2-dimensional MPC } \\
\hline PC2 of CHs $1,2,3,4,5 \& 7$ & 60.1 & 64.4 & 1964.4 & 80.8 & 85.1 & 1978.8 \\
\hline $\mathrm{PC} 2$ of $\mathrm{CHs} 1,2,3,4 \& 7$ & 59.3 & 63.7 & 1953.5 & 80.5 & 84.9 & 1971.8 \\
\hline PC2 of CHs $2,3,4 \& 5$ & 59.6 & 63.8 & 1943.2 & 80.5 & 84.9 & 1948.4 \\
\hline PC2 of $\mathrm{CHs} 3,4 \& 5$ & 59.7 & 63.9 & 1928.3 & 79.3 & 84.3 & 1935.5 \\
\hline PC2 of CHs $3 \& 4$ & 46.7 & 52.3 & 1846.9 & 63.3 & 71.7 & 1793.6 \\
\hline \multirow{2}{*}{\multicolumn{7}{|c|}{$\begin{array}{l}\text { (c) from } 2 \text { June } 1989 \text { to } 28 \text { May } 1993 \\
\text { 12-dimensional MPC }\end{array}$}} \\
\hline & & & & & & \\
\hline $\mathrm{PC} 1, \mathrm{PC} 2, \mathrm{PC} 3, \mathrm{PC} 4 \& \mathrm{PC} 5$ & 56.2 & 61.8 & 1995.8 & 91.3 & 94.4 & 1997.6 \\
\hline PC1,PC2,PC4 \& PC5 & 54.7 & 60.4 & 1938.2 & 91.8 & 94.5 & 1996.6 \\
\hline PC4 \& PC5 & 52.5 & 59.1 & 1950.4 & 83.3 & 88.5 & 1965.9 \\
\hline \multicolumn{7}{|l|}{ 2-dimensional $M P C$} \\
\hline PC2 of CHs $1,2,3,4,5 \& 7$ & 60.0 & 67.2 & 1972.6 & 86.8 & 91.2 & 1991.4 \\
\hline PC2 of CHs $1,2,3,4 \& 7$ & 57.7 & 65.1 & 1963.8 & 84.9 & 89.9 & 1987.2 \\
\hline PC2 of CHs 2,3,4 \& 7 & 55.0 & 62.3 & 1940.4 & 84.3 & 89.5 & 1982.9 \\
\hline $\mathrm{PC} 2$ of $\mathrm{CHs} 3,4 \& 7$ & 52.7 & 60.2 & 1917.1 & 83.6 & 89.0 & 1977.6 \\
\hline PC2 of CHs $3 \& 4$ & 41.0 & 49.4 & 1850.5 & 68.7 & 78.8 & 1893.0 \\
\hline
\end{tabular}

technique has an important advantage to summarize dynamic information of change within image over a period. Even though the MPC needs some extra computing time, it would be compensated by saving classification time. Besides, direct multidate classification needs too many bands, so that it needs many trial-and-errors to select the best multidate band combination. To use the MPC technique based on quantitative approach as described here, it's advisable first to superimpose the delta brightness and delta greenness that displayed in red and green guns respec- tively. Areas of no-change will appears mid-yellow, the increasing amount of vegetation (natural growth and new artificial regeneration) appears green, while forest cutting appears red or very bright yellow. If the tone or reflectance difference between the areas of change and no-change is not clearly shown, it's better to ignore quantitative classification using MPC. As also suggested by many other authors, this study shows that the visual inspection of the final change detection map could not be absolutely ignored to fill in the within-field gaps of automated classification 
Table 7 Confusion matrix of the final change detection category based on 12-dimensional MPC using the synthetic bands defined as delta brightness, delta grenness, stable brightness and stable greenness components.

(c) from 10 June 1986 to 2 June 1989

\begin{tabular}{rrrrrrrrrr}
\hline $\begin{array}{c}\text { Class } \\
\text { Number } \\
\text { of pixel }\end{array}$ & C1 & C2 & C3 & C4 & C5 & C6 & C7 & $\begin{array}{l}\text { Producer's } \\
\text { accuracy }\end{array}$ \\
\hline C1 & 134 & 126 & 0 & 0 & 8 & 0 & 0 & 0 & 94.03 \\
C2 & 294 & 0 & 294 & 0 & 0 & 0 & 0 & 0 & 100.00 \\
C3 & 97 & 0 & 0 & 92 & 0 & 0 & 5 & 0 & 94.85 \\
C4 & 81 & 11 & 0 & 2 & 65 & 0 & 1 & 2 & 80.25 \\
C5 & 121 & 0 & 0 & 0 & 0 & 121 & 0 & 0 & 100.00 \\
C6 & 139 & 0 & 0 & 0 & 0 & 0 & 139 & 0 & 100.00 \\
C7 & 583 & 0 & 35 & 0 & 0 & 0 & 0 & 548 & 94.00 \\
\hline User's accuracy & 92.0 & 89.4 & 97.9 & 89.0 & 100.0 & 95.9 & 99.6 &
\end{tabular}

Change categories: C1:P3,S2/3-OC; C2:OC-S0/S0s-S0d/S0-S1; C3:B-S; C4:PF/DC-B/C/E; C5:SV-DV; C6: $\mathrm{DV}-\mathrm{B} / \mathrm{C} / \mathrm{E}$; and $\mathrm{C} 7: \mathrm{NC}$

(b) from 10 June 1986 to 28 May 1993

\begin{tabular}{|c|c|c|c|c|c|c|c|c|c|c|}
\hline Class & $\begin{array}{l}\text { Number } \\
\text { of pixel }\end{array}$ & $\mathrm{C} 1$ & $\mathrm{C} 2$ & $\mathrm{C} 3$ & $\mathrm{C} 4$ & $\mathrm{C} 5$ & $\mathrm{C} 6$ & $\mathrm{C} 7$ & $\mathrm{C} 8$ & $\begin{array}{l}\text { Producer's } \\
\text { accuracy }\end{array}$ \\
\hline $\mathrm{C} 1$ & 97 & 94 & 0 & 0 & 0 & 0 & 0 & 0 & 3 & 96.91 \\
\hline $\mathrm{C} 2$ & 91 & 0 & 85 & 6 & 0 & 0 & 0 & 0 & 0 & 93.41 \\
\hline C3 & 56 & 0 & 5 & 51 & 0 & 0 & 0 & 0 & 0 & 91.07 \\
\hline $\mathrm{C} 4$ & 50 & 0 & 4 & 0 & 46 & 0 & 0 & 0 & 0 & 92.00 \\
\hline C5 & 99 & 0 & 0 & 0 & 0 & 99 & 0 & 0 & 0 & 100.00 \\
\hline C6 & 204 & 38 & 0 & 0 & 3 & 1 & 157 & 0 & 5 & 76.96 \\
\hline $\mathrm{C} 7$ & 109 & 0 & 6 & 5 & 3 & 0 & 0 & 95 & 0 & 87.16 \\
\hline $\mathrm{C} 8$ & 492 & 0 & 3 & 3 & 0 & 0 & 0 & 0 & 486 & 98.78 \\
\hline User's ac & curacy & 71.2 & 82.5 & 78.5 & 88.5 & 99.0 & 100.0 & 100.0 & 98.4 & \\
\hline
\end{tabular}

Change categories: C1:P3,S2/3-OC; C2:S0S-S0d; C3:S0-S1; C4:OC-S0; C5:B-S; C6:PF/DC-B/C/E; C7:SV$\mathrm{DV}$; and $\mathrm{C} 8 \mathrm{NC}$

(c) from 2 June 1989 to 28 May 1993

\begin{tabular}{ccrrrrrrrr}
\hline \multicolumn{2}{c}{$\begin{array}{c}\text { Class Number } \\
\text { of pixel }\end{array}$} & C1 & C2 & C3 & C4 & C5 & C6 & C7 & $\begin{array}{c}\text { Producer's } \\
\text { accuracy }\end{array}$ \\
\hline C1 & 25 & 25 & 0 & 0 & 0 & 0 & 0 & 0 & 100.00 \\
C2 & 123 & 0 & 120 & 0 & 0 & 0 & 0 & 3 & 97.56 \\
C3 & 69 & 0 & 0 & 69 & 0 & 0 & 0 & 0 & 100.00 \\
C4 & 50 & 1 & 0 & 0 & 45 & 0 & 4 & 0 & 90.00 \\
C5 & 102 & 0 & 0 & 6 & 6 & 96 & 0 & 0 & 94.12 \\
C6 & 141 & 0 & 0 & 2 & 2 & 0 & 139 & 0 & 98.58 \\
C7 & 629 & 0 & 47 & 0 & 0 & 0 & 0 & 582 & 92.53 \\
\hline User's accuracy & 96.2 & 71.9 & 89.6 & 100.0 & 100.0 & 97.2 & 99.5 & \\
\hline
\end{tabular}

Change categories: C1:P3,S2/3-OC; C2:S0s-S0d/S0S1; C3:B-S; C4:PF/DC-B/C/E; C5:SV-DV; C6:DV$\mathrm{B} / \mathrm{C} / \mathrm{E}$; and $\mathrm{C} 7: \mathrm{NC}$ 


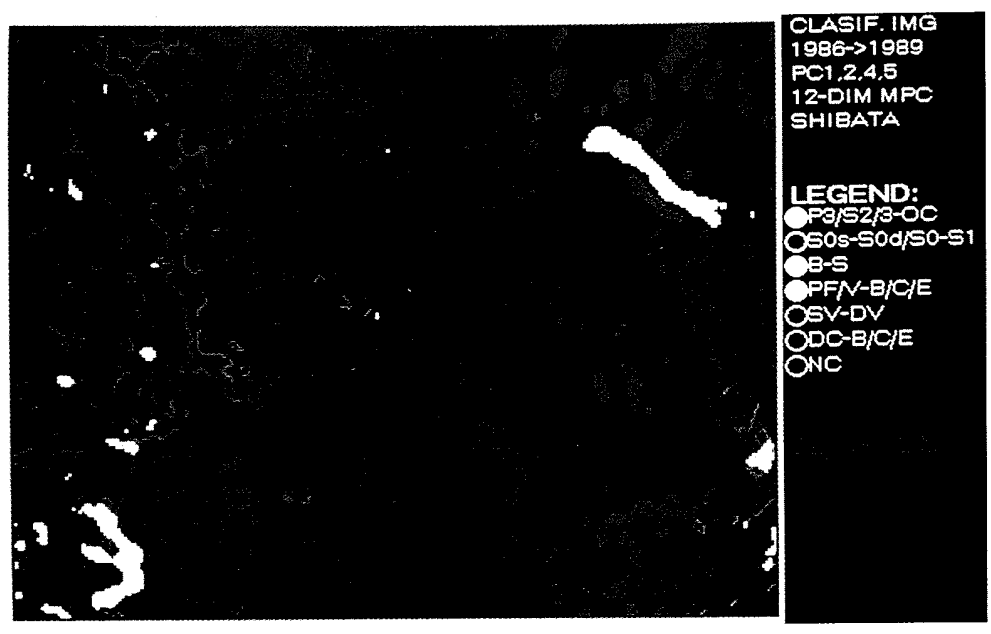

(a)

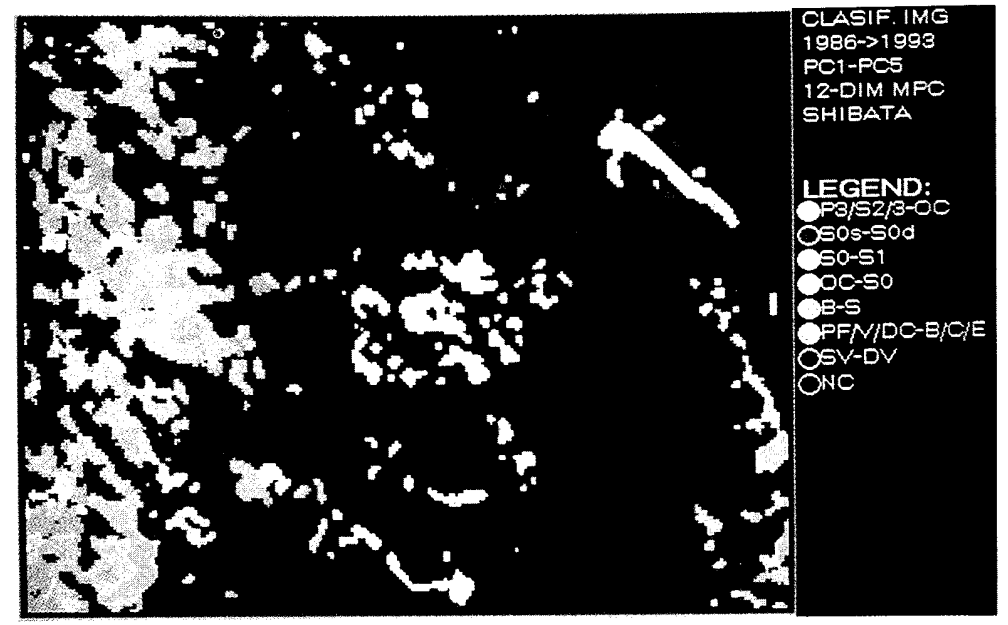

(b)

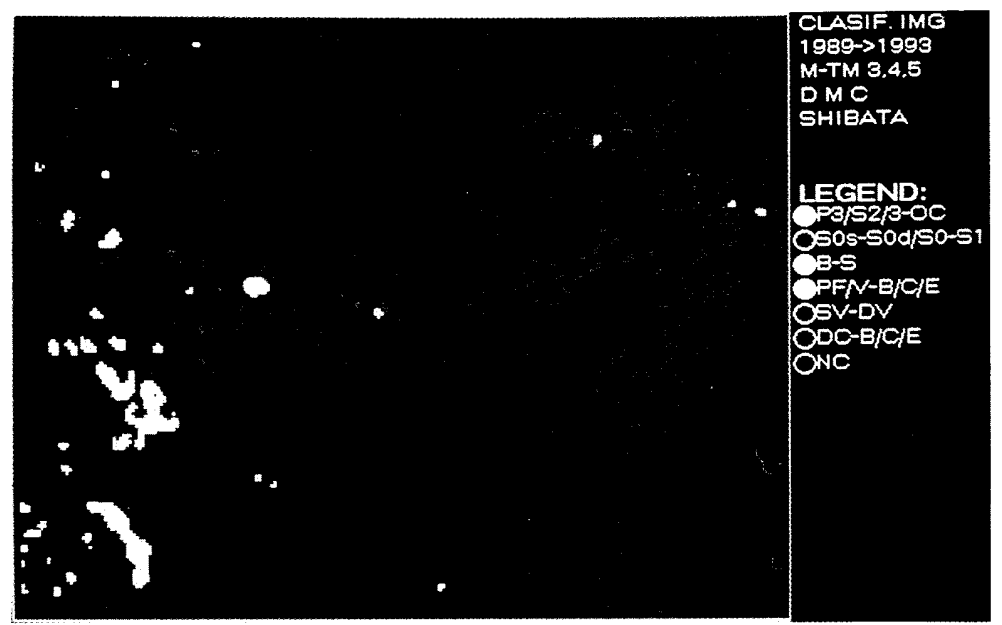

(c)

Fig. 3 The final change detection maps: (a) from 10 June 1986 to 2 June 1989, (b) from 10 June 1986 to 28 May 1993 and (c) from 2 June 1989 to 28 May 1993. The areas shown are approximately $7.3 \mathrm{~km} \times 5.7 \mathrm{~km}$. 
that misclassified into no-change category and remove the small areas of overestimate change.

For future requirements of forest monitoring within this area, it is suggested that a time series of TM data from another month or season when uninterested objects, e.g., unmelted snow is absent (for example, September or October) is required to reduce this considerable confusion.

\section{CONCLUSION}

From the results of this study, the following conclusions were derived:

1) The study reemphasized the fact that TM data can be used to accurately monitor the distribution and types of forest cover change, especially the natural growth of young forest plantations and artificial regeneration activity. Specifically for the study area, differences in the density of understory vegetation that invades the seedling stage of J. cedar are factors which influence the misclassification between $\mathrm{S}_{\mathrm{S}}-\mathrm{S}_{\mathrm{d}}$ and $\mathrm{S} 0-\mathrm{S} 1$. Although these results provided an insufficient basis for broad generalization, the TM data and quantitative approach using the MPC technique have shown promising results for monitoring forest plantation change. As time intervals become longer, the ability to detect forest cover change due to natural growth increases. The fact that during longer time intervals, i.e. between 1986 and 1993 (7 years) beside detecting the recent clearcuts or forest conversion, the changes from clearcuts to artificial regeneration (OC-S0) and growth from S0 to S1 were monitored. The ability to detect S0-S1 was due to the accumulation of a large amount of standing green foliage during the time interval as tree growth.

2) Of the three change detection techniques examined in this study, the DMC consistently provided high accuracy. For the 1986-1989 and 1986-1993 date pairs, the 12-dimensional MPC is preferable because it can: (1) reduce the dimensionality of data, (2) effectively pick up the change of interest which is mapped in several components and (3) provide a relatively high accuracy.

\section{ACKNOWLEDGEMENT}

The invaluable direction of Professor Toshio SENOO, of the Kyoto Prefectural University, from the beginning of our study is deeply acknowledged. Thanks are due to reviewers who made many useful comments on the earlier draft of this paper. This study was conducted while the first author held the Japanese Government (Monbusho) Scholarship program.

\section{LITERATURE CITED}

Adeniyi, P.O., (1985): Digital analysis of multitemporal Landsat data for land-use/land-cover classification in semi-arid area of Nigeria. Photogrammetric Engineering and Remote Sensing 51 (11):1761-1774 Alwashe, M.A. and BoKhari, A.Y., (1993): Monitoring vegetation changes in Al Madinah, Saudi Arabia, using Thematic mapper data. International Journal of Remote Sensing 14 (2):191-197

AWAYA, Y.,HÄME, T. and TANAKA, N., (1994): Vegetation change detection using Landsat data in Northern Finland, A test case using smoothing and Laplacian filtering. Proc. NIPR. Symp. Polar. Biol. 7:270-282

Byrne, G.R., Crapper, P.F. and Mayo, K.K., (1980): Monitoring land cover changes by principal components analysis of multitemporal Landsat data. Remote Sensing of Environment 10:175-184

Chusnie, J.L. and Atkinson, P., (1985): Effect of spatial filtering on scene noise and boundary detail in Thematic Mapper imagery. Photogrammetric Engineering and Remote Sensing 51 (9):1483-1493 Conaglton, R.G., Oderwald, R.G. and Mead, R.A., (1983): Assessing Landsat classification accuracy using discrete multivariate analysis statistical techniques. Photogrammetric Engineering and Remote Sensing 49 (12):1671-1678

EKSTRAND, S.P., (1990): Detection of moderate damage on Norway spruce using Landsat TM and digital stand data. IEEE Transactions on Geoscience and Remote Sensing 28 (4):685-691

FORAN, B.D., (1987): Detection of yearly cover change with Landsat MSS on pastoral landscapes in central Australia. Remote Sensing of Environment 23:333-350

FUnG, T., (1990): An assessment of TM Imagery for land-cover change detection. IEEE Transactions on Geoscience and Remote Sensing 28 (4):681-684

FunG, T. and LEDrew, E., (1988): The determination of optimal threshold levels for change detection using various accuracy indices. Photogrammetric Engineering and Remote Sensing 54 (10):1449-1454

GonZalez, R.C. and Winrz, P., (1988): Digital image processing. Addison - Wesley Publishing Company, Massachusetts 503pp

Hallum, C., (1993): A change detection strategy for monitoring vegetative and land-use cover types using remotely-sensed, satellitebased data. Remote Sensing of Environment 43:171-177

HowarTh, P.J. and Wickware, G.M., (1981): Procedures for change detection using Landsat digital data. International Journal of Remote Sensing 2 (3):277-291

Hudson, W.D. and Ramm, C., (1987): Correct formulation of the Kappa coefficient of agreement. Photogrammetric Engineering and Remote Sensing 53 (4) 421-422

IngEbritsen, S.E. and Lyon, R.J.P., (1985) : Principal component analysis of multitemporal image pairs. International Journal of Remote Sensing 6 (5): 687-696

JAYA, I N.S. and Kobayashi, S., (1994): Forest change detection using multitemporal principal component algorithm. Proceeding of NAFRO seminar on sustainable forestry and its biological environment. Japan Society of Forest Planning Press, 19-34

JAYA, I N.S. and KoBAYASHI, S., (1995): Classification of detailed forest types based upon the separability algorithm: A case study in the Yahiko Mountain and Shibata Forest areas, Niigata Prefecture. Journal of The Remote Sensing Society of Japan 15 (1):40-53

\section{J. For. Plann. 1:23-38 (1995)}


Jensen, J.R., (1986):Introductory digital image processing. Prentice Hall, Englewood Cliffs, New Jersey, 379pp

Jensen, J.R., Cowen, D.J., Althausen, J.D., Narumalani, S. and Weatherbee, O., (1993): An evaluation of the Coast Watch change detection protocol in South Carolina. Photogrammetric Engineering and Remote Sensing $\mathbf{5 9}$ (6) 1039-1046

JIAU, L., (1988): Development of principal component analysis applied to multitemporal Landsat TM data. International Journal of Remote Sensing 9 (12):1895-1907

NARENDRA, P.M., (1981): A separable median filter for image noise smoothing. IEEE Transactions on Pattern Analysis and Machine Intelligence PAMI-3 (1):20-29

NELSON. R.F., (1983): Detecting forest change due to insect activity using Landsat MSS. Photogrammetric Engineering and Remote Sensing $4 \mathbf{9}(9): 1303-1314$

Pylon, P.G., Howarth, P.J., Bullock, R.A. and Adeniyi, P.O., (1988): An enhanced classification approach to change detection in semiarid environments. Photogrammetric Engineering and Remote Sens ing 54 (12):1709-1716

RiCHARDS, J.A., (1984): Thematic mapping from multitemporal image data using principal component transformation. Remote Sensing of Environment 16:35-46

Richards, J.A., (1993): Remote sensing digital image processing: An
Introduction. Springer-verlag, Berlin. 281pp

Richardson, A.J. and WiEgAnd, C.L., (1977): Distinguishing vegetation from soil background information. Photogrammetric engineering and Remote Sensing 43 (12):1541-1552

Rosenfield, G. and Fitzpatrick-Lins, K., (1986): A coefficient of agree ment as a measure of thematic classification accuracy. Photogrammetric Engineering and Remote Sensing 52(2):223-227

SENOO, T., (1994): A monitoring system for forest management using multi-temporal remote sensing data. Bull. Kyoto Pref. Univ. For. 38: $77-87$

SinGH, A., (1989): Digital change detection techniques using remotelysensed data. International Journal of Remote Sensing 10 (6):986-1003 Tucker, C.J., (1978): A comparison of satellite sensor bands for vegetation inventory and monitoring. Photogrammetric Engineering and Remote Sensing 44 (11):1369-1380

Tucker, C.J. and Maxwell, E.L., (1976): Sensor design for monitoring vegetation canopies. Photogrammetric Engineering and Remote Sensing 42 (11): 1399-1410

Weismiller, R.A., Kristof , S.J., Scholz, D.K., Anuta, P.E. and Momin, S.A., (1977): Change detection in coastal zone environments. Photogrammetric Engineering and Remote Sensing 43 (12):1533-1539

(Received 6 April 1995)

(Accepted 11 July 1995) 